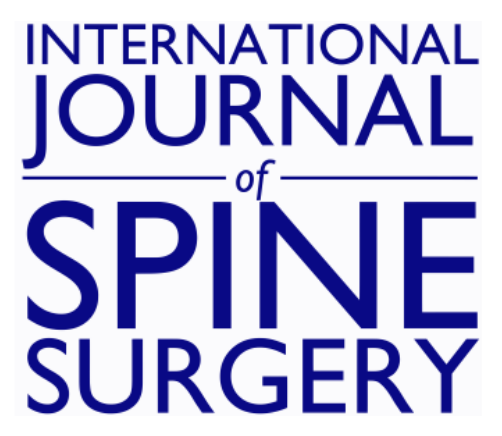

\title{
The Effect of Esophageal Temperature Probes on Postoperative Dysphagia Following Primary Anterior Cervical Discectomy and Fusion: A Randomized Prospective Study
}

Rahul G. Samtani, Daniel Huttman, Jeffrey H. Weinreb, Matthew Cyriac, Warren Yu and Joseph R. O'Brien

Int J Spine Surg 2021, 15 (4) 676-682

doi: https://doi.org/10.14444/8089

http://ijssurgery.com/content/15/4/676

This information is current as of April 26, 2023.

Email Alerts Receive free email-alerts when new articles cite this article. Sign up at: http://ijssurgery.com/alerts 


\title{
The Effect of Esophageal Temperature Probes on Postoperative Dysphagia Following Primary Anterior Cervical Discectomy and Fusion: A Randomized Prospective Study
}

\author{
RAHUL G. SAMTANI, MD, ${ }^{1}$ DANIEL HUTTMAN, MD ${ }^{2}$ JEFFREY H. WEINREB, MD,${ }^{2}$ MATTHEW \\ CYRIAC, MD, MBA, ${ }^{2}$ WARREN YU, MD, ${ }^{2}$ JOSEPH R. O'BRIEN, MD, $\mathrm{MPH}^{2}$ \\ ${ }^{1}$ University of Wisconsin Hospitals and Clinics, Department of Orthopedic Surgery and Rehabilitation, Madison, Wisconsin, ${ }^{2}$ Department of Orthopaedic Surgery, \\ George Washington University, Washington, DC
}

\begin{abstract}
Background: The anterior approach to the cervical spine is associated with postoperative dysphagia. It is difficult to predict which patients are most at risk for dysphagia. The objective of this study was to determine if placing an esophageal temperature probe preoperatively would affect the severity and length of postoperative dysphagia. We hypothesize that use of an esophageal temperature probe would result in worse postoperative dysphagia at all measured time points as measured by the Swallowing-Quality of Life (SQAL-QOL) survey after anterior cervical discectomy and fusion (ACDF).

Methods: A total of 44 patients were enrolled in a prospective, randomized controlled trial and randomized into groups: 1 with an esophageal temperature probe placed at the time of surgery and 2 without. A total of 39 patients filled out postoperative SWAL-QOL questionnaires at their preoperatives. Using the survey results, the data were analyzed between groups and subanalyzed based on number of operative levels and sex.

Results: SWAL-QOL scores for patients undergoing 2-level ACDF with an esophageal temperature probe were significantly better compared with those without a probe at 2 weeks and 6 months postoperatively. These results were not significant at other time points in in the overall analysis, but a trend toward improved dysphagia scores at each time point postoperatively was seen with the probe group. No differences were found between the 2 groups with respect to age at the time of surgery, sex, and preoperative SWAL-QOL score.

Conclusions: Placement of an esophageal temperature probe at the time of surgery significantly improved postoperative dysphagia scores in patients undergoing 2-level ACDF at 2 weeks and 6 months postoperatively.

Level of Evidence: 2

Clinical Relevance: Placement of a temperature probe is a safe and effective technique that is readily available and easily applicable to the practice of spine surgery and may improve postoperative dysphagia after ACDF.
\end{abstract}

Cervical Spine

Keywords: dysphagia, anterior cervical discectomy and fusion, SWAL-QOL, esophageal temperature probe

\section{INTRODUCTION}

The anterior approach to the cervical spine is one of the most commonly used approaches in the treatment of cervical spine pathology, including anterior cervical discectomy and fusion (ACDF). ${ }^{1}$ This approach, first described by Cloward and then popularized by Robinson and Smith, uses the interval between the sternocleidomastoid and strap muscles of the neck. ${ }^{2,3}$ Dissection is then continued through the deep cervical fascia between the carotid sheath laterally and the trachea and esophagus medially.

Although this approach is nearly ubiquitous in the treatment of the cervical spine, it is not without complications. One of the most frequently reported complications following anterior cervical surgery is dysphagia. Previous reports vary greatly in the incidence of dysphagia with some as low as $2 \%$ to as high as $60 \% .^{4-10}$ Furthermore, the dysphagia can persist for months to years following surgery, leading to long-term morbidity. ${ }^{8,11}$ Most importantly, determining which patients will develop postoperative dysphagia and for what period of time can be difficult if not impossible to predict. Several factors increasing the likelihood of postoperative dysphagia have been identified, including female gender, multiple-level surgery, age, preoperative 
Table 1. The 14-item Swallowing-Quality of Life questionnaire.

\begin{tabular}{|c|c|c|c|c|c|}
\hline Symptoms & Almost Always & Often & Sometimes & Hardly Ever & Never \\
\hline 1. Coughing & 1 & 2 & 3 & 4 & 5 \\
\hline 2. Choking when eating food & 1 & 2 & 3 & 4 & 5 \\
\hline 3. Choking when drinking & 1 & 2 & 3 & 4 & 5 \\
\hline 4. Having thick saliva or phlegm & 1 & 2 & 3 & 4 & 5 \\
\hline 5. Gagging & 1 & 2 & 3 & 4 & 5 \\
\hline 6. Drooling & 1 & 2 & 3 & 4 & 5 \\
\hline 7. Problems chewing & 1 & 2 & 3 & 4 & 5 \\
\hline 8. Having excess saliva or phlegm & 1 & 2 & 3 & 4 & 5 \\
\hline 9. Having to clear your throat & 1 & 2 & 3 & 4 & 5 \\
\hline 10. Food sticking in your throat & 1 & 2 & 3 & 4 & 5 \\
\hline 11. Food sticking in your mouth & 1 & 2 & 3 & 4 & 5 \\
\hline 12. Food or liquid drippling out of your mouth & 1 & 2 & 3 & 4 & 5 \\
\hline 13. Food or liquid coming out of your nose & 1 & 2 & 3 & 4 & 5 \\
\hline 14. Coughing food or liquid out of your mouth when it gets stuck & 1 & 2 & 3 & 4 & 5 \\
\hline
\end{tabular}

swallowing difficulties, surgery involving the third cervical vertebra, increasing plate thickness, and failure of hardware. ${ }^{7,8,10,12-16}$ While once believed to be a result of intubation, recent studies lack evidence to show that intubation alone contributes to postoperative dysphagia. ${ }^{8,17}$

The objective of this study was to determine if the presence of an esophageal temperature probe present at the time of surgery alters the severity of postoperative dysphagia. The severity of dysphagia was monitored from preoperatively through the 1year postoperative time period with the use of the Swallowing-Quality of Life (SWAL-QOL) survey, a validated measure of dysphagia. ${ }^{18-20}$ We chose to use a 14-question dysphagia specific portion of the SWAL-QOL survey that has been used in a previous study of dysphagia in spine surgery. ${ }^{17}$

\section{MATERIALS AND METHODS}

Prior to initiation of the study, approval was obtained from the institutional review board (no. 041136). The patients were recruited into the study at the time of their preoperative visit. After obtaining informed consent, patients were randomly assigned into one of two groups through concealed envelope allocation.

The first group (probe) were patients who had an 18 French Level 1 Acoustascape esophageal stethoscope with temperature sensor probe (Smiths Medical ASD Inc, Weston, Massachusetts) inserted into the esophagus after successful intubation in the operating room with the probe remaining for the duration of the procedure. The temperature probe is made out of latex-free polyvinyl chloride, and measures $6 \mathrm{~mm}$ in diameter (18 French). The second group of patients (non-probe) had no temperature probe placed into the esophagus and had their temperature monitored with a Crystalline II skin temperature sensor (Sharn Inc, Tampa, Florida) during surgery. Each patient was asked to fill out a dysphagia-specific SQAL-QOL questionnaire preoperatively and at 2 weeks, 6 weeks, 3 months, 6 months, and 1 year postoperatively. The dysphagiaspecific SWAL-QOL contains 14 items that relate to the patient's ability to swallow and are rated from 1 (worst) to 5 (best), with a worst possible score of 14 and a best possible score of 70 (Table 1). ${ }^{17}$

All patients in the study underwent primary ACDF by 1 of the 2 senior authors of the study (JRO, WDY) from June 2011 to March 2012. Patients undergoing revision surgery and those undergoing surgery for acute trauma were excluded from recruitment. Patients who were unable to complete the SWAL-QOL questionnaire at each time point were excluded from final analysis.

Surgery was performed using standard technique. Shadow-line retractors were placed under the longus coli during surgery. Both surgeons made use of Caspar pins. Plates used during surgery included the Globus XTEND plate or the SpineFrontier Invue plate. The Globus plate (Globus Medical Inc, Audubon, Pennsylvania) is $2.3 \mathrm{~mm}$ thick, while the SpineFrontier plate (SpineFrontier, Inc, Beverly, Massachusetts) is $2.6 \mathrm{~mm}$ thick.

Dysphagia scores were calculated by summation of each item in the 14-item scale ranging from a possible low score of 14 to a possible high score of 70. Lower scores indicate more frequent symptoms of dysphagia.

\section{Statistical Methods}

Data analysis began with measures of central tendency (means, medians) and dispersion (standard deviation, range) for continuous variables, such as age and SWAL-QOL score and frequency counts 
Table 2. Summary of data.

\begin{tabular}{|c|c|c|c|c|c|}
\hline Statistic & No Probe & Probe & $\begin{array}{c}P \text { Value Between Probe } \\
\text { and No-Probe Group }\end{array}$ & $\begin{array}{c}\text { No Probe, } P \text { Value } \\
\text { Compared to Preoperative }\end{array}$ & $\begin{array}{c}\text { Probe, } P \text { Value } \\
\text { Compared to Preoperative }\end{array}$ \\
\hline Average age, y & 49 & 52 & .28 & & \\
\hline Male:female ratio & $6: 12$ & $15: 6$ & .51 & & \\
\hline Average preoperative score & 63.67 & 63.67 & 1 & & \\
\hline \multicolumn{6}{|l|}{ Postoperative } \\
\hline $2 \mathrm{wk}$ & 53.17 & 58.29 & .069 & .0001 & .002 \\
\hline $6 \mathrm{wk}$ & 60.17 & 62.1 & .44 & .092 & .212 \\
\hline $3 \mathrm{mo}$ & 61.33 & 64.14 & .22 & .292 & .667 \\
\hline $6 \mathrm{mo}$ & 63.11 & 66.33 & .15 & .815 & .008 \\
\hline $1 \mathrm{y}$ & 65.94 & 67.05 & .48 & .217 & .003 \\
\hline Male, $2 \mathrm{wk}$ & 54.33 & 57.83 & .443 & .0084 & .55 \\
\hline Female, $2 \mathrm{wk}$ & 52.58 & 58.47 & .11 & .0035 & .0004 \\
\hline Female, 1 y & 66.83 & 67.8 & .523 & .025 & .027 \\
\hline \multicolumn{6}{|l|}{2 levels postoperative } \\
\hline $2 \mathrm{wk}$ & 48.5 & 57.89 & .043 & .0021 & .045 \\
\hline $6 \mathrm{mo}$ & 62 & 67.78 & .039 & 1 & .039 \\
\hline $1 \mathrm{y}$ & 65.5 & 68.22 & .134 & .173 & .003 \\
\hline
\end{tabular}

Bold values indicate $P$ Value $<.05$.

for categorical variables, including sex and number of levels operated on. Analysis continued with both within-group and between-group comparisons of SWAL-QOL scores at each time point. Withingroup analysis was performed with paired $t$ tests comparing preoperative scores with each postoperative score time point to detect differences with respect to time and recovery from dysphagia. Between-group analysis included independent $t$ tests comparing scores between groups at each individual time point to detect differences at each time point. Categorical data were analyzed with chi-square analysis. Further subgroup analysis was performed for males and females as well as the number of levels fused during surgery.

\section{RESULTS}

Twenty-one patients in the probe group and 18 patients in the non-probe group completed surveys at each study time point and were included in the final analysis for a final follow-up of $89 \%$ of patients initially enrolled. The probe and non-probe groups were similar with respect to age at the time of surgery (52 versus 49 years; $P=.28$ ), male:female ratio $(P=.51)$, and preoperative score (63.7 versus 63.7; $P=1$ ), respectively (Table 2 ).

In the probe group, a statistically significant decrease in dysphagia score was seen at 2 weeks postoperatively $(P<.05)$, and a statistically significant improvement in dysphagia score was seen at both 6 months and 1 year postoperatively ( $P$ $<.05)$. The dysphagia score in this group was not significantly different from preoperative values at any other time point and improved to the preoperative score by 3 months postoperatively (Table 3 ).

In the non-probe group, a statistically significant decrease in the dysphagia score was seen at 2 weeks postoperatively $(P<.05)$. At no other time point did the dysphagia score significantly differ from the preoperative score, and the average postoperative score did not improve to preoperative baseline until 1 year postoperatively (Table 4 ).

Overall analysis of scores between groups at each time point overall revealed a trend toward improved dysphagia scores for the probe group compared with the non-probe group, although the difference never reached statistical significance (Figure 1).

Subgroup analysis revealed that patients in the probe group undergoing 2-level ACDF had statistically significantly improved $(P<.05)$ dysphagia scores at 2 weeks and 6 months postoperatively compared with those in the non-probe group undergoing the same surgery. Also, patients in the probe group undergoing 2-level ACDF had significantly improved dysphagia scores at 1 year postoperatively compared with their preoperative scores (Figure 2). No statistically significant differences were seen at any time point between the 2 groups for patients undergoing 1- or 3-level ACDF.

Analysis of female data revealed that patients in both groups had a statistically significant $(P<.05)$ decrease in dysphagia score at 2 weeks postoperatively and a statistically significant $(P<.05)$ improvement in dysphagia scores at 1 year postoperatively compared with their preoperative scores. No differences were seen between the groups at any time point. 
Table 3. Data for patients with an esophageal probe.

\begin{tabular}{|c|c|c|c|c|c|c|c|c|c|}
\hline Patient No. & Age & Sex & Surgery & Preoperative Score & 2 Weeks & 6 Weeks & 3 Months & 6 Months & 1 Year \\
\hline 1 & 65 & $\mathrm{~F}$ & C5-7 ACDF & 64 & 65 & 70 & 68 & 70 & 70 \\
\hline 2 & 47 & $\mathrm{~F}$ & C4-5 ACDF & 63 & 61 & 64 & 66 & 67 & 68 \\
\hline 3 & 61 & M & C4-7 ACDF & 48 & 50 & 51 & 56 & 56 & 60 \\
\hline 4 & 71 & $\mathrm{~F}$ & C4-7 ACDF & 70 & 67 & 69 & 66 & 68 & 69 \\
\hline 5 & 44 & M & C6-7 ACDF & 67 & 68 & 68 & 69 & 69 & 69 \\
\hline 6 & 52 & M & C5-7 ACDF & 69 & 50 & 58 & 61 & 69 & 69 \\
\hline 7 & 43 & $\mathrm{~F}$ & C5-7 ACDF & 59 & 52 & 57 & 65 & 66 & 67 \\
\hline 8 & 57 & $\mathrm{M}$ & C6-7 ACDF & 57 & 65 & 65 & 65 & 66 & 67 \\
\hline 9 & 52 & $\mathrm{~F}$ & C5-7 ACDF & 64 & 64 & 67 & 70 & 70 & 70 \\
\hline 10 & 59 & $\mathrm{~F}$ & C5-7 ACDF & 63 & 60 & 62 & 64 & 68 & 68 \\
\hline 11 & 44 & M & C5-7 ACDF & 63 & 67 & 65 & 66 & 67 & 66 \\
\hline 12 & 39 & $\mathrm{~F}$ & C5-6 ACDF & 68 & 64 & 61 & 64 & 64 & 66 \\
\hline 13 & 66 & $\mathrm{~F}$ & C4-5 ACDF & 66 & 52 & 63 & 61 & 68 & 69 \\
\hline 14 & 39 & $\mathrm{~F}$ & C5-6 ACDF & 70 & 54 & 70 & 70 & 70 & 70 \\
\hline 15 & 52 & M & C3-6 ACDF & 59 & 47 & 51 & 57 & 58 & 60 \\
\hline 16 & 58 & $\mathrm{~F}$ & C5-7 ACDF & 53 & 45 & 51 & 55 & 63 & 64 \\
\hline 17 & 49 & $\mathrm{~F}$ & C5-6 ACDF & 63 & 48 & 51 & 53 & 58 & 56 \\
\hline 18 & 45 & $\mathrm{~F}$ & C5-7 ACDF & 67 & 56 & 59 & 65 & 67 & 70 \\
\hline 19 & 56 & $\mathrm{~F}$ & $\mathrm{C} 4-5 \mathrm{ACDF}$ & 65 & 61 & 70 & 70 & 70 & 70 \\
\hline 20 & 39 & $\mathrm{~F}$ & $\mathrm{C} 5-7 \mathrm{ACDF}$ & 69 & 62 & 70 & 68 & 70 & 70 \\
\hline 21 & 57 & $\mathrm{~F}$ & C4-7 ACDF & 70 & 66 & 62 & 68 & 69 & 70 \\
\hline
\end{tabular}

Abbreviation: ACDF, anterior cervical discectomy and fusion.

Analysis of male data revealed a statistically significant $(P<.05)$ decrease from preoperative dysphagia score only in males in the non-probe group at 2 weeks postoperatively. No statistically significant differences were found between the 2 groups at any time point, although the average score in the non-probe group did not return to baseline at 1 year, while the probe group returned to baseline by 3 months (Table 2).

No statistically significant differences were seen at any time point when comparing dysphagia scores postoperatively between males and females.

\section{DISCUSSION}

Dysphagia is a common problem after anterior cervical spine surgery. A number of risk factors and intraoperative factors have been previously identified; however, this is the first study to examine placement of an esophageal temperature probe. Placement of an esophageal temperature probe or oral-gastric tube is commonly done to facilitate identification of the relatively soft and shapeless esophagus. At the inception of this study, the senior author postulated that a temperature probe or oralgastric tube would provide a hard object that would allow the cervical retractors to press against, thereby bruising the luminal wall of the esophagus. The current study refutes the initial postulate but instead raises another possibility: the structured but pliable polyvinyl chloride catheter of the temperature probe may allow the esophagus to maintain its lumen and translate away from the retractors as opposed to

Table 4. Data for patients without an esophageal probe.

\begin{tabular}{|c|c|c|c|c|c|c|c|c|c|}
\hline Patient No. & Age & Sex & Surgery & Preoperative Score & 2 Weeks & 6 Weeks & 3 Months & 6 Months & 1 Year \\
\hline 1 & 41 & $\mathrm{~F}$ & C5-7 ACDF & 55 & 56 & 70 & 70 & 70 & 70 \\
\hline 2 & 46 & $\mathrm{~F}$ & C4-7 ACDF & 62 & 65 & 67 & 68 & 68 & 69 \\
\hline 3 & 58 & $\mathrm{M}$ & C6-7 ACDF & 63 & 61 & 63 & 63 & 65 & 67 \\
\hline 4 & 50 & M & C5-7 ACDF & 67 & 50 & 50 & 61 & 62 & 68 \\
\hline 5 & 58 & $\mathrm{~F}$ & C4-7 ACDF & 63 & 58 & 65 & 67 & 68 & 69 \\
\hline 6 & 49 & M & C5-7 ACDF & 62 & 56 & 67 & 67 & 66 & 68 \\
\hline 7 & 60 & $\mathrm{~F}$ & C4-7 ACDF & 65 & 59 & 62 & 67 & 69 & 68 \\
\hline 8 & 46 & $\mathrm{~F}$ & C4-7 ACDF & 56 & 50 & 60 & 61 & 66 & 66 \\
\hline 9 & 54 & $\mathrm{M}$ & C5-7 ACDF & 66 & 57 & 62 & 63 & 64 & 64 \\
\hline 10 & 42 & $\mathrm{~F}$ & C6-7 ACDF & 70 & 68 & 69 & 69 & 70 & 70 \\
\hline 11 & 38 & $\mathrm{~F}$ & C5-6 ACDF & 65 & 56 & 54 & 44 & 57 & 66 \\
\hline 12 & 55 & $\mathrm{~F}$ & C4-6 ACDF & 70 & 53 & 58 & 60 & 60 & 64 \\
\hline 13 & 56 & $\mathrm{~F}$ & C5-7 ACDF & 55 & 33 & 44 & 53 & 55 & 64 \\
\hline 14 & 62 & M & C4-7 ACDF & 69 & 52 & 66 & 48 & 37 & 48 \\
\hline 15 & 39 & M & C3-5 ACDF & 67 & 50 & 57 & 67 & 70 & 70 \\
\hline 16 & 43 & $\mathrm{~F}$ & C4-7 ACDF & 67 & 41 & 68 & 66 & 70 & 70 \\
\hline 17 & 41 & $\mathrm{~F}$ & C5-7 ACDF & 54 & 33 & 39 & 42 & 49 & 56 \\
\hline 18 & 45 & $\mathrm{~F}$ & C3-4 ACDF & 70 & 59 & 62 & 68 & 70 & 70 \\
\hline
\end{tabular}

Abbreviation: ACDF, anterior cervical discectomy and fusion. 


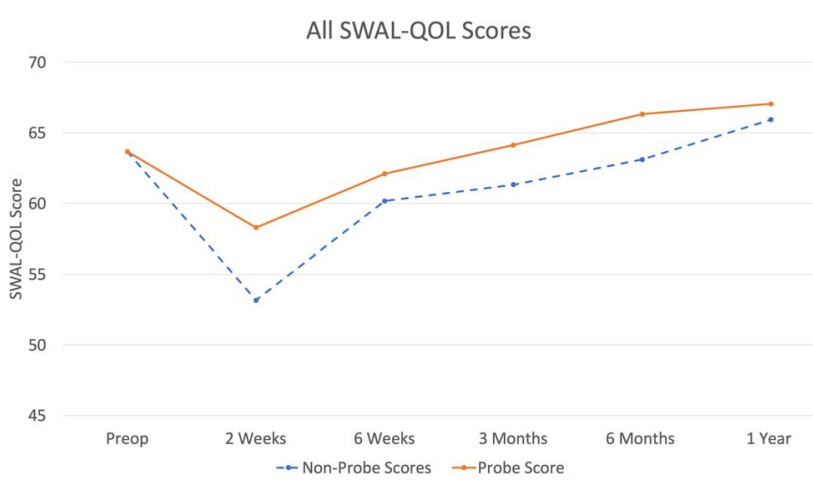

Figure 1. All Swallowing-Quality of Life scores.

folding in on itself and becoming crushed (Figures 3 and 4).

To our knowledge, this is the first study to evaluate the effects of esophageal temperature probe at the time of surgery on the severity of postoperative dysphagia following primary ACDF. Previous studies have shown that anterior cervical surgery is in itself a risk factor for the development of dysphagia, and multiple possible risk factors have been identified. ${ }^{17}$ The aim of this study was to evaluate whether the presence of esophageal temperature probe during surgery and retraction on the esophagus could mitigate or worsen the postoperative course.

The data in this study do correlate with previously published reports of postoperative dysphagia occurring in the early postoperative time period and resolving over time. However, recovery is not as full in the non-probe group, pointing to an interesting finding in this study in that an esophageal temperature probe may have a protective effect against postoperative dysphagia. Those patients in the non-probe group continued to have lower average scores compared with the probe group at each time point, and their scores did not improve to preoperative baseline until 1 year postoperatively, while those in the probe group recovered to their

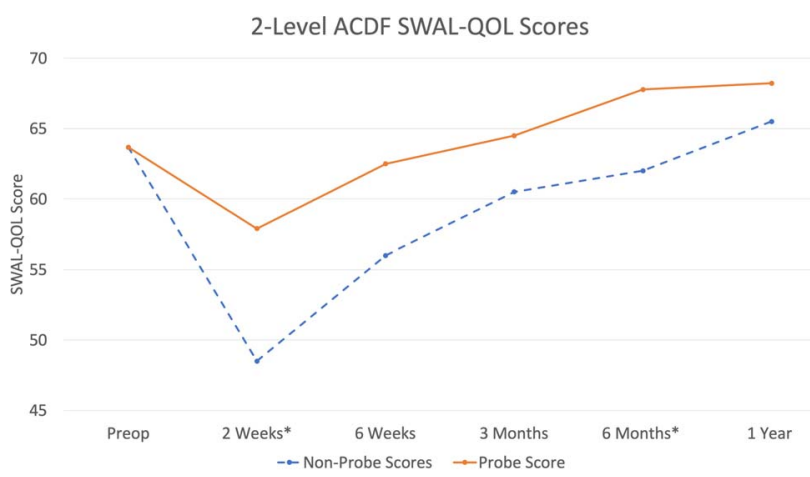

Figure 2. 2-level anterior cervical discectomy and fusion Swallowing-Quality of Life scores.

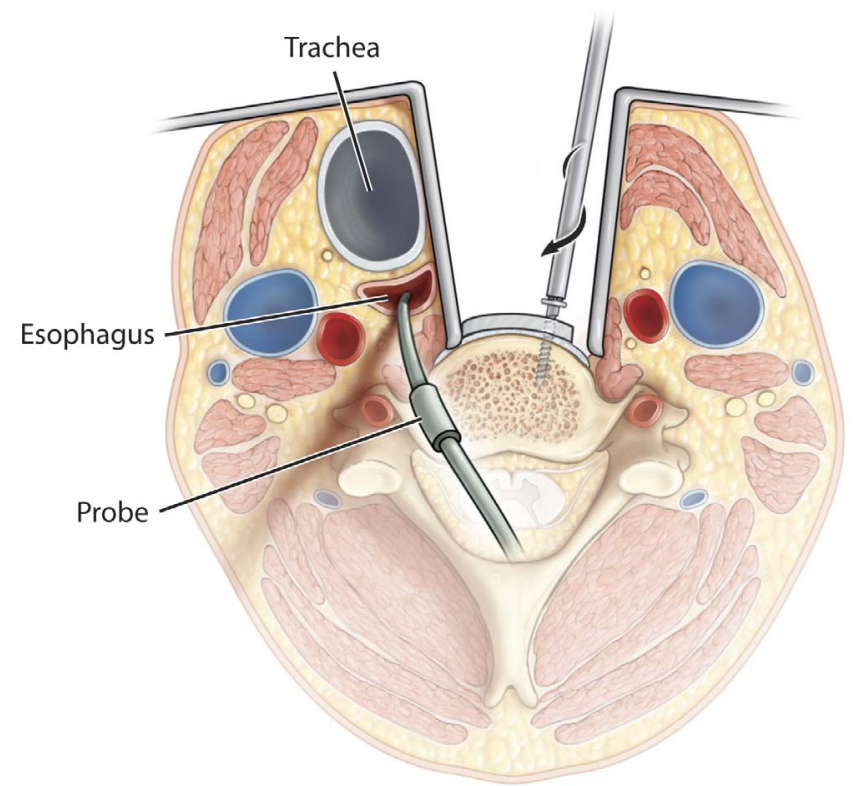

Figure 3. Anterior approach with temperature probe in place and patent esophagus.

preoperative baseline score by 3 months postoperatively.

The implication that an esophageal probe is protective against postoperative dysphagia is further supported by subgroup analysis. This analysis showed that in those undergoing 2-level ACDF, a statistically significant improvement in postoperative dysphagia scores was seen in the probe group as compared with the non-probe group at 2 weeks and 6 months. In analyzing the female patients, who are known to be at risk for dysphagia, statistically

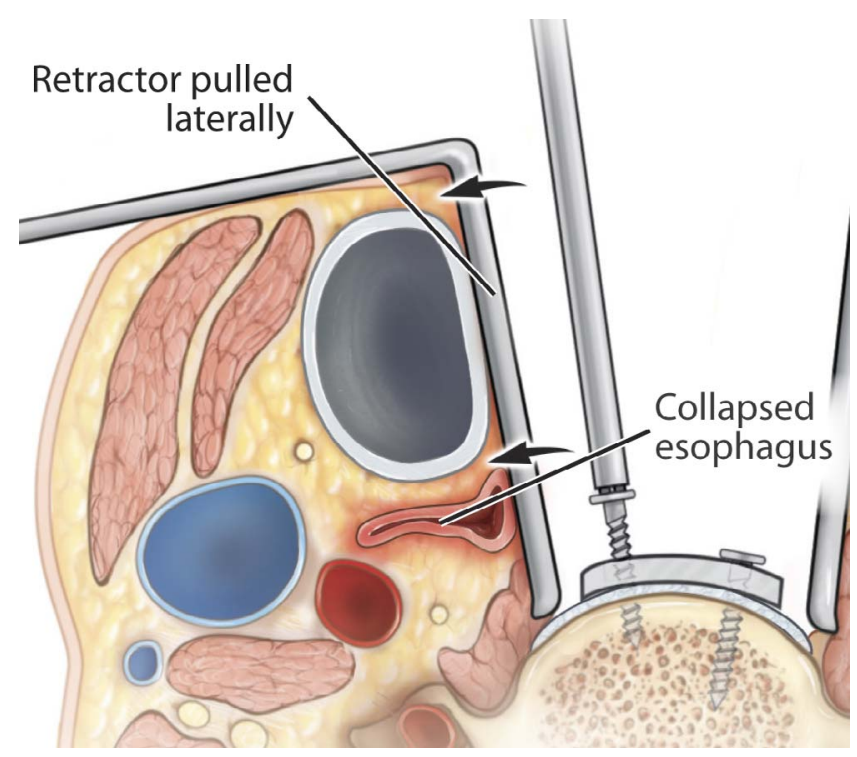

Figure 4. Anterior approach with no temperature probe in place and resulting collapsed esophagus. 
significant decreases in dysphagia scores in the early postoperative period were seen in both groups. However, while no statistically significant differences were seen between the 2 groups at any time point for women, a trend with better scores postoperatively at every time point was seen in the probe group. Also, men who underwent the procedure were shown to have a statistically significant decrease from preoperative score in the early postoperative period only in the non-probe group, indicating more severe dysphagia. An additional explanation is that the total retractor time, not the number of levels fused, was the primary predictor in the development of dysphagia. In general, 2-level fusions are more likely to have a longer retractor time, but variation within the 1- and 2-level groups may exist.

At 1 year postoperatively, dysphagia scores had improved from baseline in each group. This supports the previous evidence that cervical spondylotic disease and anterior cervical osteophytes may contribute to the symptoms of dysphagia preoperatively. ${ }^{17,21,22}$

The strengths of this study include the randomization process, specific inclusion criteria, and consistent follow-up and data collection with the use of a validated outcome measurement. Limitations of this study include the relatively small sample size, which potentially limited the power of the study, specifically in regard to the subgroup analysis. While a trend was seen at each time point favoring the probe group's dysphagia scores, no statistically significant differences were seen that may have been brought out with larger numbers. Another limitation is the lack of measuring dysphagia with the use of a radiographic or endoscopic swallow study. This would have allowed for further correlation between the subjective dysphagia scores and these objective means of measurement.

\section{CONCLUSIONS}

Placement of an esophageal temperature probe in this study is shown to statistically improve postoperative dysphagia scores at 2 weeks and 6 months postoperatively compared with those without temperature probe in the esophagus at the time of 2level ACDF surgery. Furthermore, while no statistically significant differences were seen overall, a trend toward better scores at each time period postoperatively was seen in the group of patients with a probe in place during surgery compared with those without a probe in place. Additionally, placement of an esophageal probe may allow quicker recovery from postoperative dysphagia. These data demonstrate a protective effect of an esophageal temperature probe during ACDF surgery on postoperative dysphagia. Placement of a probe is a technique that is readily available and easily applicable to the practice of spine surgery.

\section{REFERENCES}

1. Angevine PD, Arons RR, McCormick PC. National and regional rates and variation of cervical discectomy with and without anterior fusion, 1990-1999. Spine (Phila Pa 1976). 2003. doi:10.1097/01.brs.0000058880.89444.a9

2. Cloward RB. History of the anterior cervical fusion technique. J Neurosurg. 1985;63(5):817-819.

3. Robinson R. Anterolateral disc removal and interbody fusion for cervical disc syndrome. Bull Johns Hopkins Hosp. 1955;96:223-224.

4. Caspar W, Barbier DD, Klara PM. Anterior cervical fusion and Caspar plate stabilization for cervical trauma. Neurosurgery. 1989;25(4):491-502.

5. Saunders RL, Bernini PM, Shirrefks TG, Reeves AG. Central corpectomy for cervical spondylotic myelopathy: a consecutive series with long-term follow-up evaluation. $J$ Neurosurg. 1991;74(2):163-170.

6. Stewart M, Johnston RA, Stewart I, Wilson JA. Swallowing performance following anterior cervical spine surgery. Br J Neurosurg. 1995;9(5):605-610.

7. Frempong-Boadu A, Houten JK, Osborn B, et al. Swallowing and speech dysfunction in patients undergoing anterior cervical discectomy and fusion: a prospective, objective preoperative and postoperative assessment. Clin Spine Surg. 2002;15(5):362-368.

8. Smith-Hammond CA, New KC, Pietrobon R, Curtis DJ, Scharver CH, Turner DA. Prospective analysis of incidence and risk factors of dysphagia in spine surgery patients: comparison of anterior cervical, posterior cervical, and lumbar procedures. Spine (Phila Pa 1976). 2004;29(13):1441-1446.

9. Winslow CP, Winslow TJ, Wax MK. Dysphonia and dysphagia following the anterior approach to the cervical spine. Arch Otolaryngol Neck Surg. 2001;127(1):51-55.

10. Bazaz R, Lee MJ, Yoo JU. Incidence of dysphagia after anterior cervical spine surgery: a prospective study. Spine (Phila Pa 1976). 2002;27(22):2453-2458.

11. Yue W-M, Brodner W, Highland TR. Persistent swallowing and voice problems after anterior cervical discectomy and fusion with allograft and plating: a 5-to 11-year followup study. Eur Spine J. 2005;14(7):677-682.

12. Lee MJ, Bazaz R, Furey CG, Yoo J. Risk factors for dysphagia after anterior cervical spine surgery: a two-year prospective cohort study. Spine J. 2007;7(2):141-147.

13. Winslow CP, Meyers AD. Otolaryngologic complications of the anterior approach to the cervical spine. Am J Otolaryngol. 1999;20(1):16-27.

14. Chin KR, Eiszner JR, Adams SB Jr. Role of plate thickness as a cause of dysphagia after anterior cervical. Spine (Phila Pa 1976). 2007;32(23):2585-2590.

15. Ning $X$, Wen Y, Xiao-Jian Y, et al. Anterior cervical 
locking plate-related complications; prevention and treatment recommendations. Int Orthop. 2008;32(5):649-655.

16. Mendoza-Lattes S, Clifford K, Bartelt R, Stewart J, Clark CR, Boezaart AP. Dysphagia following anterior cervical arthrodesis is associated with continuous, strong retraction of the esophagus. JBJS. 2008;90(2):256-263.

17. Siska PA, Ponnappan RK, Hohl JB, Lee JY, Kang JD, Donaldson WF III. Dysphagia after anterior cervical spine surgery: a prospective study using the swallowing-quality of life questionnaire and analysis of patient comorbidities. Spine (Phila Pa 1976). 2011;36(17):1387-1391.

18. McHorney CA, Bricker DE, Kramer AE, et al. The SWAL-QOL outcomes tool for oropharyngeal dysphagia in adults: I. Conceptual foundation and item development. Dysphagia. 2000;15(3):115-121.

19. McHorney CA, Bricker DE, Robbins J, Kramer AE, Rosenbek JC, Chignell KA. The SWAL-QOL outcomes tool for oropharyngeal dysphagiain adults: II. Item reduction and preliminary scaling. Dysphagia. 2000;15(3):122-133.

20. McHorney CA, Robbins J, Lomax K, et al. The SWALQOL and SWAL-CARE outcomes tool for oropharyngeal dysphagia in adults: III. Documentation of reliability and validity. Dysphagia. 2002;17(2):97-114.

21. Nelson RS, Urquhart AC, Faciszewski T. Diffuse idiopathic skeletal hyperostosis: a rare cause of dysphagia, airway obstruction, and dysphonia. J Am Coll Surg. 2006;202(6):938-942.

22. Giger R, Dulguerov P, Payer M. Anterior cervical osteophytes causing dysphagia and dyspnea: an uncommon entity revisited. Dysphagia. 2006;21(4):259-263.

Disclosures and COI: This project was approved by George Washington University (institutional review board no. 041136). No funds were received in support of this work. The authors report no conflict of interest concerning the materials or methods used in this study or the findings specified in this article.

Corresponding Author: Jeffrey H. Weinreb, Department of Orthopaedic Surgery, George Washington University, 2300 M Street NW, Washington, DC 20037. Phone: (202) 741-3300; Fax: (202) 7413313; Email: weinreb@gwu.edu.

Published 19 August 2021

This manuscript is generously published free of charge by ISASS, the International Society for the Advancement of Spine Surgery. Copyright (c) 2021 ISASS. To see more or order reprints or permissions, see http://ijssurgery.com. 